\section{Por onde vou começar?}

\author{
I. B a s che vis-singer \\ Tradução de JACÓ GUINSBURG
}

- Por onde vou começar? Antes de tudo, permitam que lhes diga quem eu sou. Eu sou, saibam, neto de rabi. Descender descendo do "Judeu Santo"(1). De parte de mãe, descendo do $\operatorname{Schac}^{(2)}$, descendo também do Ram'a ${ }^{(3)}$, do Raschi ${ }^{(4)}$ e efetivamente do Rei Davi. Assim reza a carta genealógica. Qual a diferença? Eu estava na Polônia em 1939, quando os nazis, apagado seja o seu nome, bombardearam Varsóvia. Fugi com os outros judeus pela ponte de Praga e saŕ a pé para Bialistock. Sou alguns anos mais jovem do que vocês, embora eu tenha a barba branca. Não vou me pôr a lhes contar aqui toda a minha biografia. Arrastei-me pela Rússia, passei fome, dormi em estações, perfiz toda a lista de aflições. Depois, em 1945, contrabandeei-me do paŕs de Stalin e consegui chegar a Lublin. Lá encontrei uma antiga namorada minha. Nosso encontro foi um milagre. Mas quando não se tem fé, não se vê milagres. Nós tínhamos para tudo uma resposta: o acaso. O mundo é um acaso, o homem é um acaso e tudo o que acontece com ele também é um acaso. Eu era, em Varsóvia, membro dos Tzaireé-Tzion (Jovens de Sion). Meu pai, paz à sua memória, era dono de uma mercearia na Rua Gentzse e eu o ajudava um pouco na loja e o resto do tempo me dedicava a assuntos de partido.

Minha garota, Tzile, era uma comunista roxa. Freqüentemente tínhamos discussões inflamadas. Quando eu não concordava com ela, muitas vezes me dizia aquilo que todos os comunistas costumavam dizer: que depois da Revolução ela iria me pendurar no primeiro poste. Mas por enquanto, antes de me pendurar, famos juntos à ópera e com freqüência entrávamos no Literatenfarain (União dos Escritores) para ouvir uma palestra. O senhor ainda não dava então conferências, mas publicava coisas nas Literarischebleter (Folhas Literárias) e nós dois, eu e Tzile, éramos leitores apaixonados das Literarische-bleter, embora eu não apreciasse o esquerdismo da publicação, ao passo que Tzile achava que ela não era suficientemente esquerdista. Nós amávamos a cultura, a literatura ídiche e tudo o mais. Freqüentávamos o teatro ídiche. No fim de contas, ela, Tzile, também era uma moça de famnlia hassídica. O pai era um hassid (devoto) do rabi de Ger. Os irmãos usavam longas peies (mechas laterais de cabelo). Todos pereceram.

Quando nos encontramos em Lublin, foi como uma espécie de Ressurreição dos Mortos. Eu tinha certeza que ela estava morta. Ela me considerava um defunto. Ela já se havia curado do comunismo. Quem vive naquele país não pode ter mais nenhuma ilusão. Mas, naturalmente, ambos continuávamos sendo o que se chama de progressistas. Eu continuei sionista, mas ela ainda acreditava que o socialismo é o remédio para todas as pragas do mundo. Stalin, sem dúvida, não prestava. Mas se Trotski tivesse ficado no poder, o Kamenev, se os bolcheviques e mencheviques se houvessem unido, a Rússia ter-se-ia tornado um paraíso. Se a vovozinha tivesse rodas, ela seria um bonde. Logo no primeiro encontro travamos uma discussão sobre a maneira de salvar o mundo, como convém a dois intelectuais. Pouco mais tarde, pegamos os trecos e nos pusemos a perambular na direção da Alemanha. Legalmente não se podia fazer nada então, não tínhamos passaporte, nem papéis. As leis deles são de tal ordem que se vocês não querem se associar a seus crimes nem ser vítimas deles, vocês são suspeitos. Já possuímos, graças a Deus, um país próprio, mas os nossos dirigentes copiaram tudo deles. Aqui não se pode, ali não se deve. Tudo é proibido. Eles fazem pouco do Schulkhan Aruch ${ }^{(5)}$, mas o Schulkhan Aruch deles - Deus me perdoe mil vezes a comparação - contém mil vezes mais proibições do que o nosso. Mas isso fica pra depois...

\section{A academia}

\section{Scholem Asch \\ Traduçăo e Apresentaçăo de JACó GUINSBURG}

Scholem Asch, o mais talentoso dos disclpulos de Peretz e o romancista ldiche mais lido internacionalmente até a ascensão do nome de I. BaschevisSinger depois da Segunda Guerra Mundial, foi em tudo o oposto de Nomberg. Isto é vistvel já em Dos schtetl (A cidadezinha), o livro que assinala a verdadeira entree artistica de Asch. Em suas mãos, o vilarejo se transforma basicamente: de um lado, Asch alarga-lhe as fronteiras, com impeto romântico, a ponto de abranger o mundo judeu e não-judeu e, de outro, firma-o no solo nativo, não como algo exótico ou anómalo, mas como um
1 lid-ha-Kodesch, denominaçăo dada ao Rabi Isakov Itzhak de Pshedborzh (1765-1813) por seus devotos.

2 Schabetai Cohn, autoridade na hahahá e comentador do Schulkhan Aruch.

3 Rabi Moisés (A) Isserlisch, exegeta e legislador rabínico do séc. XVI.

4 Rabi Salomão ben Izaac, famosc hermeneuta medieval.

5 "Mesa posta", uma das mais difundidas codificaçठes rabfnicas, de autoria de lossef Caro, no século XVI. 
fruto natural. Dos schtetl (1904) é uma saga, a primeira, da radicação e da integração da "cidadezinha" judia no habitat da Europa Oriental.

Este pulso universalizante, varrendo à sua passagem o exclusivismo provinciano da tipicidade judaica, conduziu a numerosa e multifacetada produção de Asch à eminência que alcançou. $O$ sopro épico, a riqueza de colorido, o élan narrativo pintaram uma série de telas ou, pode-se mesmo dizer, um so e grandioso afresco, em que o vulto do judeu se projetou no espaço e no tempo de sua existência coletiva. $E$, apesar de notórias falhas de psicologia, dos desmazelos de um estilo onde tudo jorra, de lapsos sensiveis na construção, nada disso consegue empanar definitivamente o brilho desta representação. De Moisés (1951) e O profeta (1955), até o East river (1946) novaiorquino, correu, com uma vitalidade nunca arrefecida, a pena do maior romântico e, talvez, romancista da literatura idiche.

Asch foi uma personalidade marcante em muitos sentidos. Impulsivo e arrojado, não hesitou em expor chagas profundas e dolorosas da sociedade judaica no leste europeu, como em Got fun Nekome e o romance Motke ganef suscitando controvérsias sucessivas, que culminaram no "escândalo" de Der man fun Natzeret (1943). Esta notável criação, possivelmente a obra-prima de Asch, segundo o critico Sch. Niger ${ }^{(1)}$, publicada primeiro em tradução inglesa e só mais tarde no original ídiche, pertence legitimamente à literatura ldiche, como seu autor sempre pretendeu. Ela flui certamente da mesma fonte de onde vieram Kidusch Ha-Schem, Di Kischufmakherin fun Castila, Der Tilim Iid ou seja, a do herolsmo sacrificial judaico. Este foi um tema ao qual Asch voltou repetidamente em suas narrativas históricas, opondo o poder físico não-judeu à elevação moral judaica, o triunfo temporário do punho na imposiçâo material da violência às vitórias mais duradouras do esplrito no ato do supremo sacrificio por seus valores. Assim como discerniu na donzela judia a santidade da Virgem (Feiticeira de Castela) e em Maria (1949), a devoção da mãe judia, encontrou no Rabi Ioschua ben Iossef de Nazaré as profundezas da piedade e da misericórdia hassídicas do rabi salmista, Ihiel, de O judeu dos Salmos (Salvação, na edição brasileira), e na paixão de Jesus o testemunho de que no martírio pela Santificação do Nome o judeu é imorredouro. Asch viu O nazareno, e mesmo $\mathrm{O}$ apóstolo (1943), como uma das grandes encarnações do "judeu sabático", herói ético-místico, messiânico, da epopéia da espiritualidade redentora do homem, a idéia moral " judio-cristâ".

Mas em suas produções realistas Asch tampouco renuncia à abnegação e à grandeza humanas, não permitindo que seus protagonistas rastejem apenas nas determinações materiais e na vida incolor de uma civilização de massas. Di Muter (A mãe, 1919), Mary, Toit Urteil, Haim Ledereres Tzurikum, a trilogia Farn Mabel sâo alguns de seus romances voltados para a atualidade, onde retrata aspectos psicossociais do judeu hodierno, mas sempre através de uma figuração maior (em uma personagem central, pelo menos) e com algum rasgo heróico-sublime e dramático.

Na verdade, toda a obra de Asch está carregada de dramaticidade. Não é pois de admirar que o drama o tenha também atraldo constantemente como meio de expressão. Um de seus primeiros êxitos internacionais, ainda antes da guerra de 1914, foi Deus da vingança ${ }^{(2)}$. Além desta, escreveu outras peças, como Koiln, Meschiachs Tzaiten, Mitn Schtrom, Schabse Tzvi (Sabatai $T z v i$ ), Der Landsman (O conterrâneo), e adaptou para o palco vários de seus romances. Alguns de seus textos marcaram época no repertório teatral tdiche e hebraico, sobretudo entre as duas grandes guerras.

1 Ver Dertzeilers un Romanistn, Sch. Niger. New York, 1946.

2 Encenada em alemăo pơ Max Reinhardt $e$ interpretada por Rudolf Schildkraut, a peça foi levada também em idiche, polones, russo, ingles, frances e italiano.

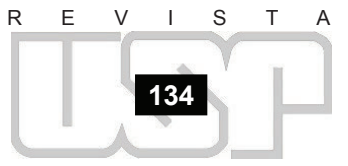

Reb Anchel-Leib era o mais destacado judeu do lugar. Seus bens incluíam a Floresta de Gastenijer, que já pertencera a seu pai, e a casa de tijolos, com duas alas, que ele mesmo construíra na cidade. Como todo judeu próspero possuía numerosa prole (Deus a guarde de mau-olhado!): seis filhos e seis filhas. Além disso, dispunha de gordo rendimento e de uma aparência simpática e, acima de tudo, pertencia à mais fina famńlia da localidade.

Reb Moiche-Ber, o pai de Reb Anchel-Leib, também fora um judeu proeminente e 
até mais proeminente que o próprio Reb Anchel-Leib, sendo, ademais, bem mais versado no Talmud. E também possuíra numerosa prole (Deus a guarde de um mau-olhado!): seis filhos e seis filhas. Também dispunha de um gordo rendimento e de uma aparência simpática, e pertencia igualmente à mais fina famflia do lugar. Mas entre pai e filho havia uma diferença: quanto maior o número de filhos, maiores as alegrias de Reb Moiche-Ber, maior o número de casamentos e circuncisões. Entretanto, quanto maior o número de filhos, maiores as aflições de Reb Anchel-Leib, maiores as tzores, maiores os vexames que lhe infligiam.

Quando fui visitá-lo, encontrei-o entregue ao estudo. Sentado numa cadeira de braços, ostentava sua magnífica barba imponentemente pousada sobre a camisa alva e engomada. No alto, pendia um retrato de seu pai Reb Moiche-Ber. Este também apresentava uma magnífica barba pousada sobre a camisa alva e engomada. Mas, em redor do velho judeu da fotografia agrupava-se um enxame de filhos e filhas, de genros e noras, de netos e bisnetos. O ancião da fotografia "afogava-se" literalmente num mar de filhos e netos que tinham brotado de seu sêmen. O oposto, porém, sucedia a seu filho, Reb Anchel-Leib. Este, sentava-se sozinho e solitário com sua magnífica barba. E eis o que ele me relatou:

- O senhor me pergunta porque me lastimo, porque estou tão triste. Em matéria de renda, diz o senhor, estou bem provido, e se eu, Reb Anchel-Leib, me lastimo e me queixo, o que devem fazer os outros? É o que o senhor diz. Bem, o que hei de lhe responder? Pergunto-lhe, por que não devo me lastimar? Que prazer me dá a minha vida? Observe o retrato no alto. Como o senhor vê, quando meu pai tinha a minha idade, ele já possuía (Deus os livre de mau-olhado!) cinco filhas casadas e cinco noras. Todos os sábados à tarde, uma multidão de netos inundava a sua casa, a fim de trazer-lhe o Gut schabes (Bom sábado). E por ocasião do Seder da Páscoa ou da festa de Purim, quando todos nós, juntamente com nossas mulheres e filhos e netos, reuníamo-nos em casa de meu pai (paz à sua memória!), não havia espaço suficiente para todos. Faltavam mesas, faltavam cadeiras para nos sentarmos. Os garçãos e os músicos não paravam um instante. Dispúnhamos até de nossa parteira particular e ela tinha trabalho "até a cabeça". E se Deus ajudava e meu pai comprava outro bosque, casava imediatamente outro filho. Instalava um negócio para um, procedia a uma circuncisão para outro. E assim, na realidade, Deus o abençoou com muitos filhos e proveu a subsistência de todos. Quanto mais velas doava à sinagoga, tanto maior a riqueza que aflúa a seu lar. Nossa famflia vivia em festa: hoje era um neto que se tornava bar mitzvá, amanhã um filho que contratava casamento, depois de amanhã outro filho que ia conhecer uma noiva em perspectiva. Em casa sempre havia o som de música, sempre havia festa.

Agora, veja o meu caso. Deus me ajudou, como ajudara a meu pai (paz à sua memória!). Também me abençoou com seis filhos e seis filhas, mas que espécie de felicidade deram-me eles? Quando eram pequenos, vivíamos preocupados com os problemas do "Gymnasia". Assim como tiveram de sofrer de catapora, sarampo e dor de dente, do mesmo modo tiveram de passar pela doença do "Gymnasia". Deus! Quanto dinheiro isto me custou! E quantas vezes, por este motivo, fui envergonhado e quantas vezes arruinaram a paz de meu sábado, o Senhor se compadeça de mim! Muito bem. Mal passamos pela doença do "Gymnasia", iniciou-se a praga da Universidade. Não quiseram admiti-los: aceitavam judeus só com medalhas de ouro. Em suma, meus filhos não conquistaram qualquer medalha de ouro e sem medalha de ouro não se podia viver!

Agora, veja o meu caso. Não obtive qualquer medalha de ouro. No entanto, estou vivo, com a ajuda de Deus. Argumentei com eles: "Vejam, apesar de tudo casei-me, tenho filhos e uma renda, com o auxílio do Senhor do Universo. Bem, vocês não conseguiram uma medalha de ouro. E dar? Casem-se então!", implorei-lhes. Mas de nada adiantou, tinha que ser a Universidade! E se não fosse aqui, seria num paŕs estrangeiro. Se necessário iriam até as Montanhas Negras, mas de alguma forma a encontrariam!

Bem, começaram a fugir de minha casa como de uma praga. Deus me livre! Em resumo, numa bela manhã dei uma olhada ao meu redor e verifiquei que não sobrara ninguém à mesa. Um partira para Berlim, outro para Paris, um terceiro para uma terra tão distante que só o diabo sabe onde fica! Sim, todos partiram, desde o mais velho até o mais moço. Este já foi, aquele vai hoje e outro irá amanhã. Afirmo-lhe, todos, até o menor estudante de "Gymnasia". E todos estudavam. Queriam aprender tudo da Alemanha, do mundo inteiro, e trazer para casa - "e você, papai, mande dinheiro"!

Deus ajudou e afinal o primeiro voltou para casa. O meu Adolfo, o mais velho, voltou. Era médico formado. Seu diploma de uma universidade estrangeira atestava que era 
médico formado. Mas, e a questão de ganhar dinheiro? Diz ele para mim: - Papai, pode me dar parabéns, consegui o diploma! - E eu lhe respondi: - Que prazer terei disso? Meu pai casou seu filho mais velho com a filha de Reb Dovidl Kalitzer e, ao que parece, estou casando o meu filho mais velho com um diploma de papel! - E ele me responde: - Papai, o senhor ainda terá orgulho de mim. - E eu lhe digo: - Quando vai ganhar algum dinheiro, meu filho? - E ele diz para mim: - Quanto ao dinheiro, papai, isto ainda está muito longe. Primeiro de tudo, tenho de passar por um exame de revalidação, e trata-se de um assunto muito duro. Mesmo depois de passar o exame de revalidação, ainda não estarei ganhando dinheiro. Pois não estudei para fazer da medicina uma carreira, mas por amor à sabedoria. O que me interessa é a ciência!

Ouvi as suas palavras e nada respondi.

Casei o meu segundo filho com a Universidade de Liège. Voltou para casa engenheiro formado. Perguntei-lhe: - Recebeu um diploma? - E ele redargüiu: - Sim, papai, recebi um diploma. - Assim, perguntei-lhe: - O que foi exatamente que você aprendeu, meu filho? - E ele me respondeu: - Papai, aprendi a construir pontes, a edificar uma ponte suspensa entre um pico de montanha e outro; e tudo que é necessário para construir uma estrada de ferro. - Assim, repliquei-lhe: - Agrada-me muito o seu gênero de trabalho: é uma coisa muito útil. Agora, diga-me, meu filho, quando começará a ganhar dinheiro? - E ele me contestou: - Quanto ao problema de ganhar dinheiro papai, isto ainda demorará muito. Primeiro devo fazer um exame de revalidação. Depois, terei de encontrar alguma companhia construtora de estradas de ferro. Mas, como em nosso país é o próprio governo que constrói as ferrovias, devo primeiro conseguir um cargo público. Mas, como o governo não aceita judeus, devo tornar-me cristão. E como não quero tornar-me cristão, Deus me livre, jamais obterei um cargo público, não poderei ganhar dinheiro. - Diante disso, indaguei ao meu filho: - Por que então estudou semelhante profissão? Por que não aprendeu algo que lhe permitisse ganhar algum dinheiro? - E ele me respondeu: - Papai, não estudei um ofício, mas uma ciência. Eu gosto de ciência.

Tornei a ouvir, sem dizer nada.

Então minha filha mais velha voltou para casa. - Filha, com quem você se casou? perguntei-lhe. - Com a Sorbonne, em Paris, papai - replicou-me. Digo-lhe, então: Gosto de sua escolha. O que estudou, minha filha? - E ela tira todo um livro em francês e me diz: - Isto, papai, eu escrevi para me tornar doutor em filosofia. - Diante destas palavras, fiquei assustado: - Pretende dizer, minha filha, que você escreveu todo este livro em francês? - Sim - respondeu-me. - E isto lhe ajudará a arrumar um marido? indaguei-lhe.

Diante disso, ela zangou-se e saiu do aposento. Sabe, a princípio, antes que fosse ao estrangeiro, moços de todos os tipos andavam atrás dela: os casamenteiros quase arrombavam minhas portas. Mas desde o seu regresso de Paris, começou a circular a notícia de que ela escrevera um livro inteiro em francês e tudo se acabou. Os moços que aparecem aqui sentem grande respeito por minha filha: na realidade, têm medo dela! Os casamenteiros agora evitam-me, e por que não haveriam de fazê-lo? Com quem poderá se casar, uma vez que escreveu todo um livro em francês?! O senhor pode imaginar como deveria ser educado o rapaz que desejasse desposá-la! Certamente sentem medo dela! E assim, como o senhor vê, ela se casou com o livro francês.

Um outro filho meu, um matemático, voltou para casa e não consegue calcular um pé cúbico da madeira que eu vendo. Ele afirma que aprendeu tudo que diz respeito à matemática, mas aquilo que eu necessito dele jamais chegou ao menos a aprender.

Logo após, outra filha voltou para casa. Ela estudou negócios econômicos em Leipzig. Tornou-se doutor em negócios econômicos. Perguntei-lhe: - Filha, gostaria de participar dos negócios? - Deus me livre! - exclamou, erguendo as mãos horrorizada. O quê!?, deseja transformar-me numa vendedora? Por que então, minha filha, tornou-se doutor em negócios econômicos? - Estudei apenas para conhecer! - Para conhecer? Eu proprio, que sou comerciante, estou sempre fugindo deste conhecimento. Sempre que tenho tempo, apanho um livro da sagrada tradição para estudar, e ela me aparece e estuda negócios econômicos por amor ao conhecimento!

Quando chega a hora do jantar, toda uma academia aboleta-se em torno de minha mesa. Aqui o senhor tem um médico e ali um engenheiro; aqui um doutor em filosofia e ali um doutor em assuntos econômicos. Todos os ramos do saber, meus filhos estudaram, e possuem diplomas de toda espécie de universidade. Com tudo isso, nenhum deles ganha um centavo ou consegue se casar. 